\title{
Developmental characteristics of pectoralis muscle in Pekin duck embryos
}

\author{
L.H. Gu${ }^{1,2}$, T.S. Xu ${ }^{1,2}$, W. Huang ${ }^{2}$, M. Xie ${ }^{2}$, W.B. Shi' ${ }^{2}$, S.D. Sun ${ }^{1}$ and \\ S.S. $\mathrm{Hou}^{2}$ \\ ${ }^{1}$ Shaanxi Key Laboratory of Molecular Biology for Agriculture, \\ College of Animal Science and Technology, Northwest A \& F University, \\ Yangling, Shaanxi, China \\ ${ }^{2}$ Institute of Animal Science, Chinese Academy of Agricultural Sciences, \\ Beijing, China \\ Corresponding author: S.D. Sun / S.S. Hou \\ E-mail: ssdsm@tom.com / houss2010@126.com
}

Genet. Mol. Res. 12 (4): 6733-6742 (2013)

Received February 15, 2013

Accepted October 17, 2013

Published December 13, 2013

DOI http://dx.doi.org/10.4238/2013.December.13.6

\begin{abstract}
To confirm the entire developmental process and transition point of embryonic Pekin duck pectoral muscle, and to investigate the association between pectoral muscle development and their regulating genes, anatomical and morphological analyses of embryonic Pekin duck skeletal muscles were performed, and the expression patterns of its regulating genes were investigated. The anatomical analysis revealed that body weight increased with age, while increases in pectoral muscle weight nearly ceased after the embryo was 20 days of hatching (E20). The developmental morphological characteristics of Pekin duck pectoral muscle at the embryonic stage showed that E20 was the transition point (from proliferation to fusion) of Pekin duck pectoral muscle. The expression patterns of MRF4, MyoG, and MSTN indicated that E19 or E20 was the fastest point of pectoral muscle development and the crucial transition for Pekin duck pectoral muscle development during the embryonic stage. Together, these findings imply that E20 is the crucial transition point (from proliferation to fusion) of Pekin duck pectoral muscle and that there is no
\end{abstract}


muscle fiber hypertrophy after E20. Results of this study provide further understanding of the developmental process and transition point of Pekin duck pectoral muscle during the embryo stage.

Key words: Pectoral muscle; Pekin duck; Embryos; Tissue sections; Expression pattern

\section{INTRODUCTION}

Skeletal muscle development is a multistep process, in which mesodermal precursor cells are selected to form myoblasts that are withdrawn from the normal cell cycle and subsequently differentiate into myotubes (Patel et al., 2002; Velleman et al., 2010). These myotubes further differentiate into muscle fibers (Buckingham, 2006; Robert et al., 2010). As the myofiber number does not increase during the postnatal period, and is determined during the embryonic stage in most animals, muscle production of adult livestock is determined during embryogenesis.

Hypertrophy of muscle fibers with the lengthening and thickening in the postnatal stage is the major event (Xu et al., 2011). Therefore, the study of muscle development during the embryonic stage is a popular research focus. A number of studies have investigated muscle development during the embryonic stage in different species (Sabourin and Rudnicki, 2000; Callis et al., 2007; Williams et al., 2009; Zhang et al., 2012). In chicken, Hartley et al. (1992) explored whether skeletal muscle satellite cells appeared during the late chicken embryo stage. In turkey, Moore et al. (2005) investigated the cross-section area of myofiber and satellite cell mitotic activity in pectoralis muscles of late-term turkey embryos. In duck, Chen et al. (2012) studied the developmental transition of pectoral muscles from late-term duck embryos to neonates. Liu et al. (2012) compared muscle weight, muscle fiber diameter, cross-sectional area, the number of myofibers per unit area (MFN), and the frequency of satellite cell activation and mitosis at the embryo stage of 27 days and at the postnatal stage of 2 days after hatching between ducks that were and were not fed insulin growth factor-1 in vivo.

However, no study has yet addressed the entire developmental process and transition points of Pekin duck pectoral muscles during the embryo stage. Improved knowledge of the developmental process and transition point of Pekin duck embryonic pectoral muscles will enhance our understanding of the mechanism of pectoral muscle development in the Pekin duck embryo. In this study, to confirm the entire developmental process and transition point of Pekin duck pectoral muscle during the embryo stage, and to investigate the association between pectoral muscle development and their regulated genes, anatomical and the morphological analyses of Pekin duck embryonic skeletal muscles were performed, and the expression patterns of their regulating genes were investigated. The results of this paper should provide further insight into the developmental process and transition points of Pekin duck pectoral muscle during the embryo stage.

\section{MATERIAL AND METHODS}

\section{Anatomy experiment}

The embryos of Pekin duck (Anas platyrhynchos domestica) were obtained from the 
breeding farm of Z-type Pekin ducks at the Institute of Animal Science (IAS), Chinese Academy of Agricultural Science (CAAS). A total of 180 eggs with $98 \pm 5 \mathrm{~g}$ weight were selected. All eggs were incubated under the same conditions at a temperature of $37^{\circ} \pm 0.5^{\circ} \mathrm{C}$ and humidity of $86-87 \%$. Ten eggs were picked out every day from 10 days after hatching (E10) to 27 days after hatching (E27). The embryos were removed from the eggs, and then the whole embryos and the pectoral muscle were weighed. The pectoral muscle rate of each embryo was calculated using the following formula: $\mathrm{PMR}=\mathrm{PMW}_{\mathrm{n}} / \mathrm{BW}_{\mathrm{n}}$, where $\mathrm{PMR}$ is the pectoral muscle rate, $\mathrm{PMW}_{\mathrm{n}}$ is the pectoral muscle weight at day $\mathrm{n}$ after hatching, and $\mathrm{BW}_{\mathrm{n}}$ is the body weight at day $n$ after hatching.

\section{Morphological analysis of pectoral muscle}

The pectoral muscle samples from six embryo stages (E11, E14, E17, E20, E23, and E26) were washed with running water and then dehydrated in a series of ethanol dilutions, i.e., $75 \%$ for $4 \mathrm{~h}, 85 \%$ for $4 \mathrm{~h}, 95 \%$ overnight, and $100 \%$ ethanol for $2 \mathrm{~h}$ with two changes. Dehydrated tissues were treated with xylene three times and then embedded into paraffin blocks, trimmed, and cut into $4 \mu \mathrm{m}$ sections. A paraffin ribbon was placed in a water bath at approximately $40^{\circ} \mathrm{C}$. Sections were mounted onto slides, air-dried for $30 \mathrm{~min}$, and then incubated at $45^{\circ} \mathrm{C}$ overnight. Sections were de-waxed with two changes of xylene for $10 \mathrm{~min}$ each and then hydrated in two changes of $100 \%$ ethanol for 3 min each, 95 and $80 \%$ ethanol for $1 \mathrm{~min}$ each, and finally, rinsed in distilled water for $5 \mathrm{~min}$. Slices were stained with hematoxylin and eosin. All sections were photographed using a digital microscope (Nikon). Five individuals were analyzed per group; five sections were studied per individual by monitoring five random fields per section. The average value of 125 myofibers was examined per bird. The myofiber diameter (MFD) and the mean number of myofibers per unit area (MFN) were measured in Image-Pro Plus 6.0 software (Media Cybernetics, Bethesda, MD, USA).

\section{Expression pattern of MRF4, MyoG, and MSTN}

Total RNA of each of the samples described above (the pectoral muscle tissues of five embryos were pooled to form a sample) was isolated with Trizol (Invitrogen, USA) following manufacturer instructions. The SYBR PrimeScript RT-PCR Kit (TaKaRa, Japan) was used for reverse transcription-polymerase chain reaction (RT-PCR), quantification of MRF4, MyoG, and MSTN cDNA, and for the detection of the two reference genes, $\beta$-actin and NADPH. Quantitative RT-PCR (qRT-PCR) was carried out with an iCycler IQ5 Multicolor Real-Time PCR Detection System (Bio-Rad, USA). The qRT-PCR reaction contained $1 \mu \mathrm{L}$ cDNA template, $12.5 \mu \mathrm{L}$ SYBR Premix Ex-Taq, $10.5 \mu \mathrm{L}$ sterile water, and $0.5 \mu \mathrm{L}$ each gene-specific primer (Table 1). The thermal cycling parameters were 1 cycle at $95^{\circ} \mathrm{C}$ for $30 \mathrm{~s}, 40$ cycles of $95^{\circ} \mathrm{C}$ for $10 \mathrm{~s}$, and $60^{\circ} \mathrm{C}$ for $40 \mathrm{~s}$. An 80 -cycle melting curve analysis was performed after each PCR run to confirm product specificity, with 1 cycle at $95^{\circ} \mathrm{C}$ for $1 \mathrm{~min}, 1$ cycle at $55^{\circ} \mathrm{C}$, and then the temperature was increased by $0.5^{\circ} \mathrm{C}$ every $10 \mathrm{~s}$ to $95^{\circ} \mathrm{C}$ while continuously monitoring fluorescence. qRT-PCR analysis of each sample was repeated three times. Moreover, to generate gene-specific standard curves, plasmids containing each gene's cDNA were serially diluted from $10^{-1}$ to $10^{-8}$, and were used as the PCR templates to detect the amplification efficiency of each primer set. Standard curve data ( $\mathrm{R}^{2}$, slope, and efficiency) are provided in Table 1. 
Table 1. Primer sequences and standard curve data for real-time quantitative PCR analysis.

\begin{tabular}{llcccc}
\hline Target gene & Primer sequence (5'-3') & Product size (bp) $\left.^{\prime}\right)$ & $\mathrm{R}^{2 \mathrm{a}}$ & Slope $^{\mathrm{b}}$ & Efficiency $^{\mathrm{c}}$ \\
\hline$\beta$-Actin & $\begin{array}{l}\text { Forward: GCTATGTCGCCCTGGATTC } \\
\text { Reverse: CACAGGACTCCATACCCAAGAA }\end{array}$ & 168 & 0.998 & -3.369 & 0.981 \\
NADPH & $\begin{array}{l}\text { Forward: AAGGCTGAGAATGGGAAAC } \\
\text { Reverse: TTCAGGGACTTGTCATACTTC }\end{array}$ & 254 & 0.999 & -3.458 & 0.946 \\
& $\begin{array}{l}\text { Forward: CGGATCACCTCCTGCCTGA } \\
\text { Reverse: CGTCCTCTAACGGCGATGCT }\end{array}$ & 87 & 0.998 & -3.354 & 0.951 \\
MRF4 & $\begin{array}{l}\text { Forward: GGAGCGCCATCAGCTACATC } \\
\text { Reverse: CGAGGAAGTCCGAGCCATT }\end{array}$ & 132 & 0.996 & -3.231 & 0.976 \\
MSTN & $\begin{array}{l}\text { Forward: GCCGACGGAGTCTGATTTC } \\
\text { Reverse: ACTCTGCCAAATACCAGTGCC }\end{array}$ & 196 & 0.997 & -3.437 & 0.979 \\
\hline
\end{tabular}

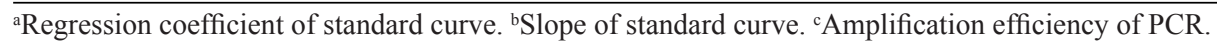

\section{Data analysis}

The relative mRNA expression levels of MRF4, MyoG, and MSTN genes were calculated using the normalized relative quantification method in BIO-RAD IQ5 software. Briefly, for each sample (three replicates per sample), mRNA expression of five genes (MRF4, MyoG, MSTN, $\beta$-actin, and NADPH) was quantified. The average threshold cycle $\left(\mathrm{C}_{\mathrm{T}}\right)$ value of each gene in each sample was calculated. The expression level of each gene at the E10 stage was used as the control $(=1)$ to calculate the relative quantity $\left(\mathrm{RQ}, \Delta \mathrm{C}_{\mathrm{T}}\right.$ method) at other stages using the formula:

$$
\mathrm{RQ}_{\text {sample }}=\mathrm{E}_{\mathrm{T}}^{\mathrm{C} \text { (control) }}-\mathrm{C}_{\mathrm{T}(\text { sample)}} \text {, }
$$

where $\mathrm{E}=$ efficiency +1 . Then, expressions of MRF4, MyoG, and MSTN genes in each stage were normalized using the relative quantity of both reference genes. The calculation formula was as follows:

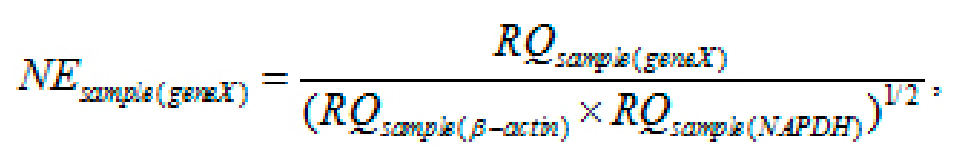

where $N E$ is the normalized expression of the gene.

\section{RESULTS}

\section{Anatomy experiment}

Figures 1 to 3 show the rough results of the anatomical analysis. Figure 1 shows that body weight increased with increasing age of Pekin duck embryos. Figure 2 shows that pectoral muscle weight development was proportional to body weight changes before E20. However, growth of the breast muscle nearly ceased after E20 (approximately $1.0 \mathrm{~g}$ ). Figure 3 shows that the pectoral muscle rate increased with increasing age before E20, and then gradually declined after that. 


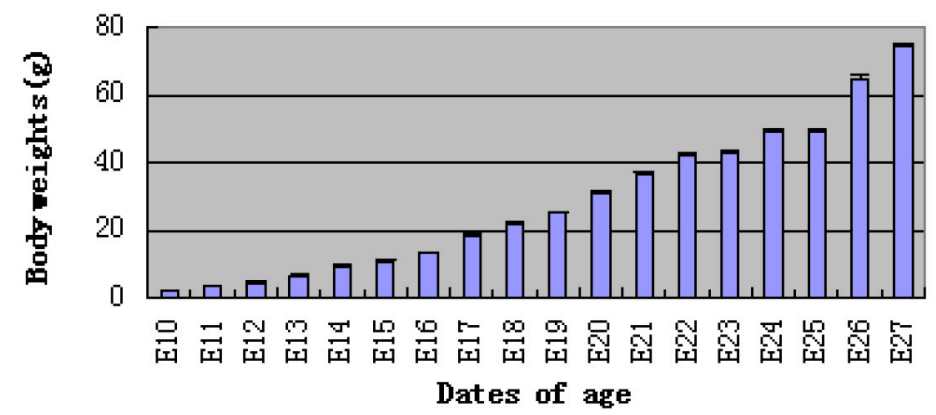

Figure 1. Growth of body weight of Pekin duck during embryos. E10 to E27 indicated embryos after 10 day hatching to embryos after 27 day hatching respectively.

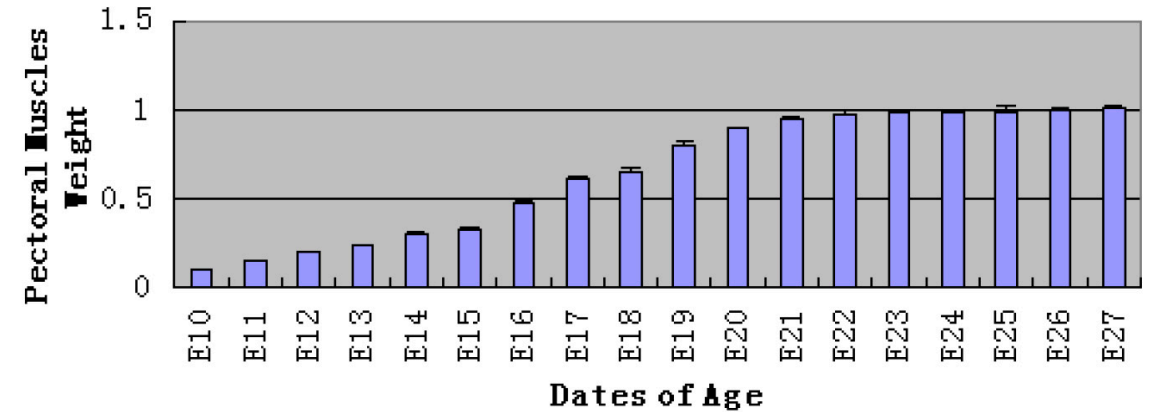

Figure 2. Growth of pectoral muscle weight of Pekin duck during embryos. E10 to E27 indicated embryos after 10 day hatching to embryos after 27 day hatching respectively.

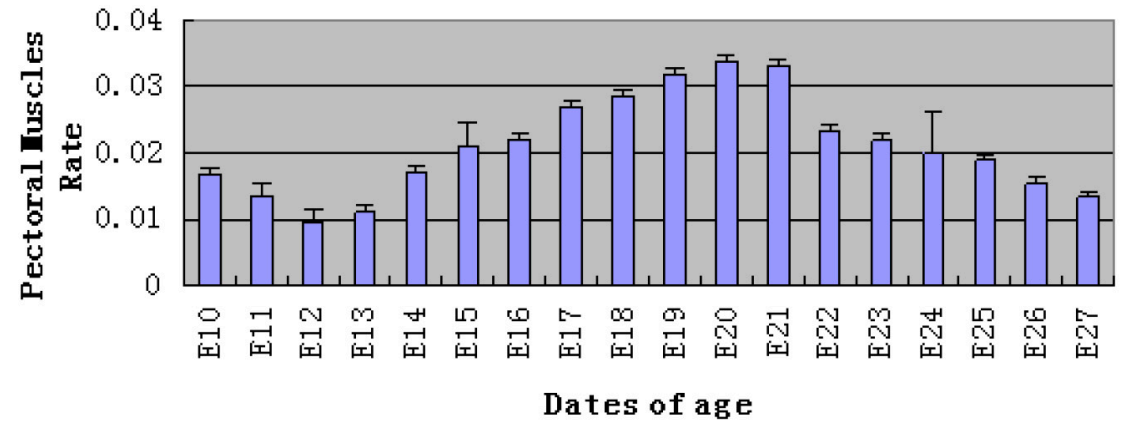

Figure 3. Pectoral muscle rate of Pekin duck during embryos. E10 to E27 indicated embryos after 10 day hatching to embryos after 27 day hatching respectively.

\section{Morphological analysis of pectoral muscle}

The process of muscle development at the embryonic stage is roughly demonstrated in Figure 4. Specifically, E11 to E17 represented the stage of proliferation, to form more mononucleated fibers, and fusing, to form multi-nucleated myotubes. At the E20 stage, myotubes 
bound to the perimysium to form myolin. With myotubes developing continuously, muscle fibers became obvious at stage E23 in pectoral muscles of Pekin duck. Subsequently, muscle fibers continued to grow in circumference, and by stage E26, they already had the same shape as muscle fibers in adult animals.
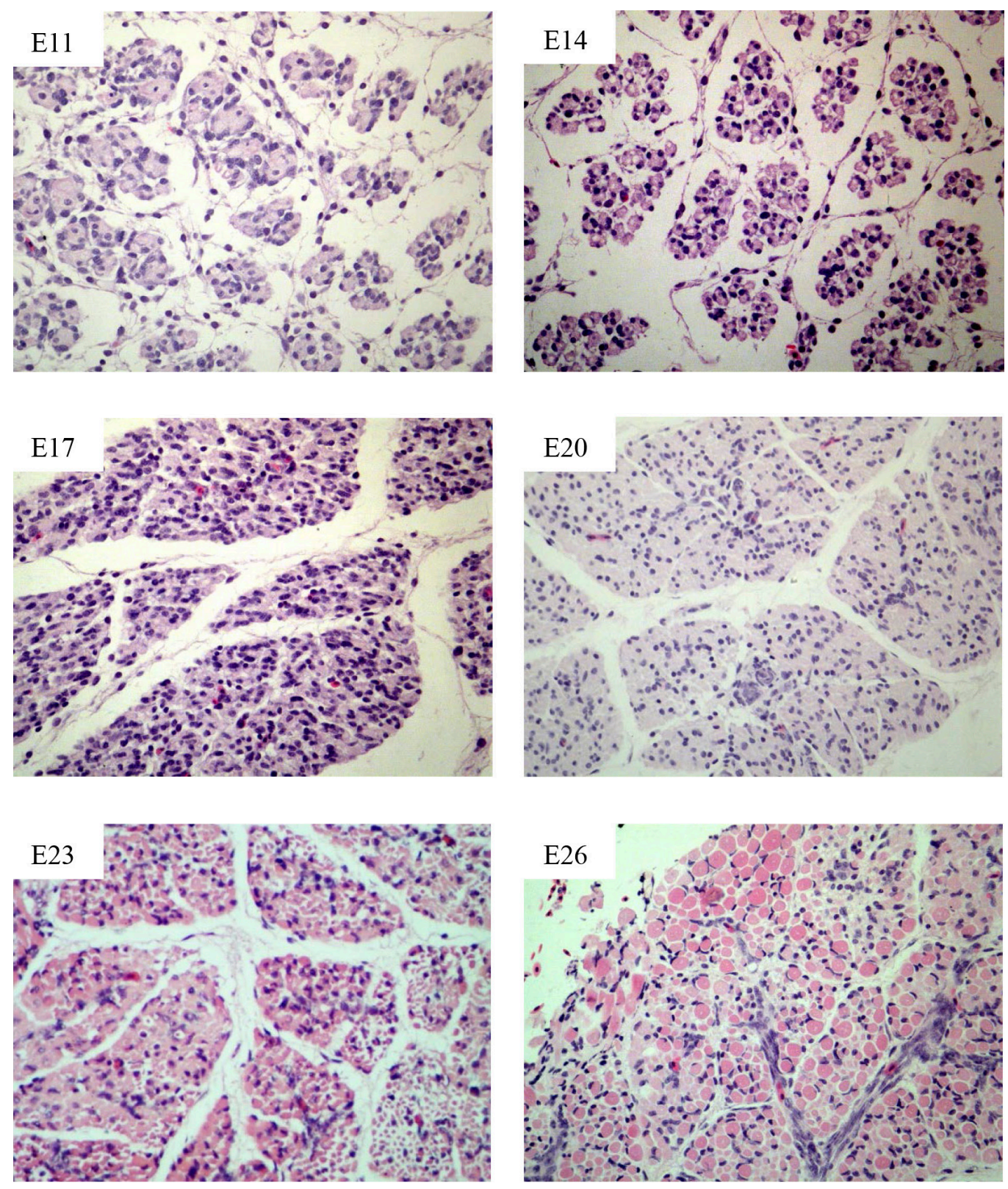

Figure 4. Cross-section of pectoral muscle in embryonic stage of Pekin duck. All the above images are amplified 400 times. 
Figure 5 and 6 show the change in pectoral muscle fiber diameter and pectoral muscle fiber number in embryonic Pekin duck pectoral muscle tissues. Muscle fiber diameters increased with increasing age of the embryos, and two significant turning points (at E16 and E21, respectively) were observed (Figure 5). Conversely, the muscle fiber number decreased during development of the embryo. Interestingly, the significant turning points of muscle fiber number also occurred at E16 and E21 (Figure 6).

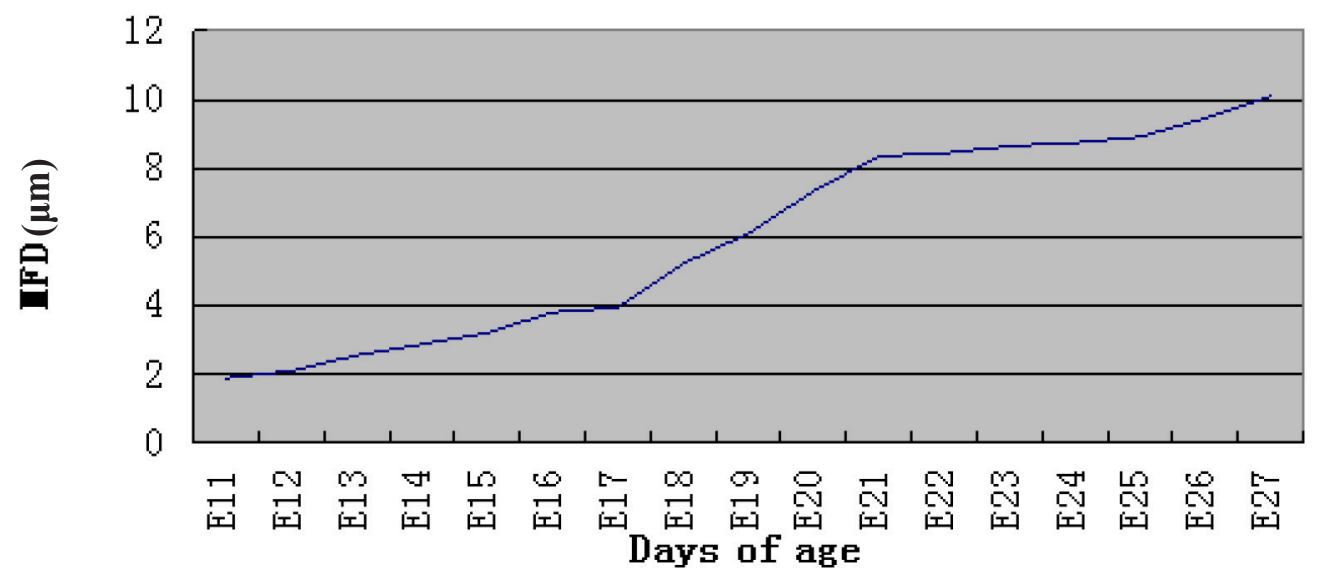

Figure 5. Myofiber diameter of pectoral muscle in embryonic stage of Pekin duck.

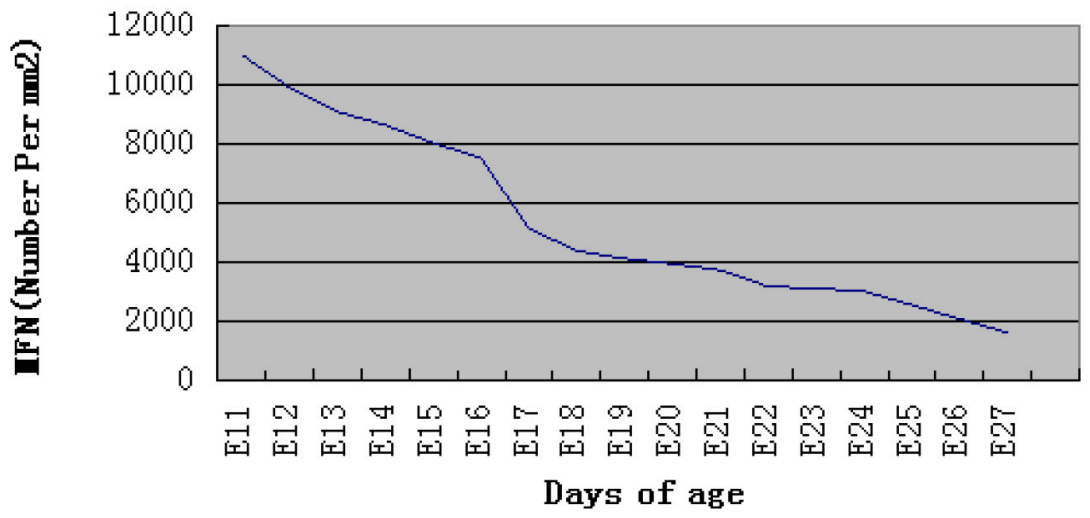

Figure 6. Myofiber number per $\mathrm{mm}^{2}$ of pectoral muscle in embryonic stage of Pekin duck.

\section{Expression profiling of MRF4, MyoG, and MSTN}

The expression levels of MRF4, MyoG, and MSTN genes were detected using qRTPCR. Figure 7 shows that the expression of MRF4 increased slowly, reached its peak value at E19, and then declined gradually. The expression of MyoG showed a similar trend as that of MRF4, and it reached its peak at E20. Conversely, the expression of MSTN declined slowly, reached its minimum value at E19, and then increased gradually (Figure 8). 


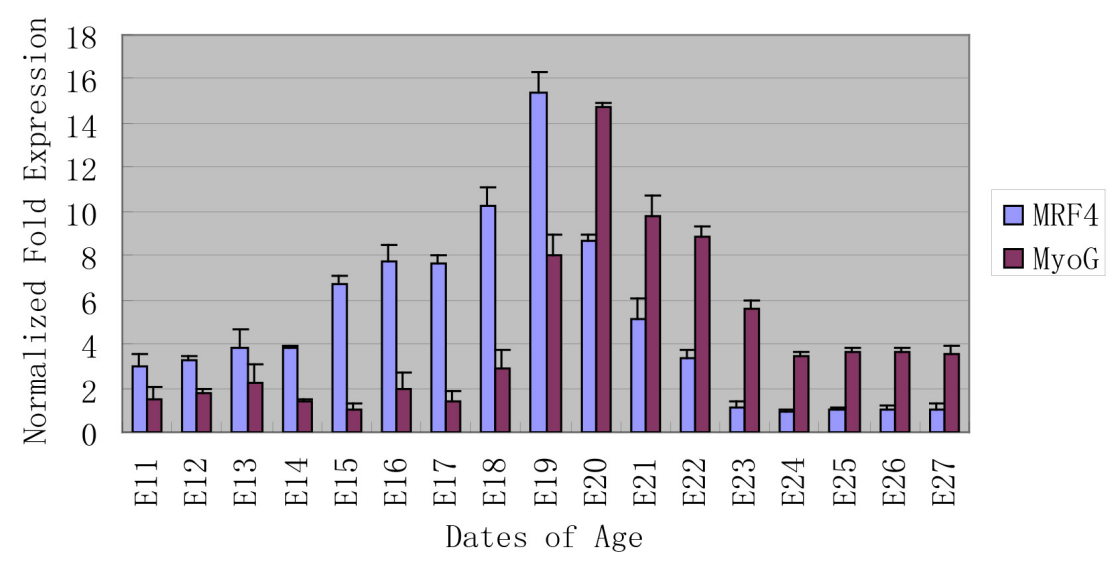

Figure 7. Relative expression level of MRF4 and MyoG genes in the pectoral muscle of embryonic stage Pekin duck.

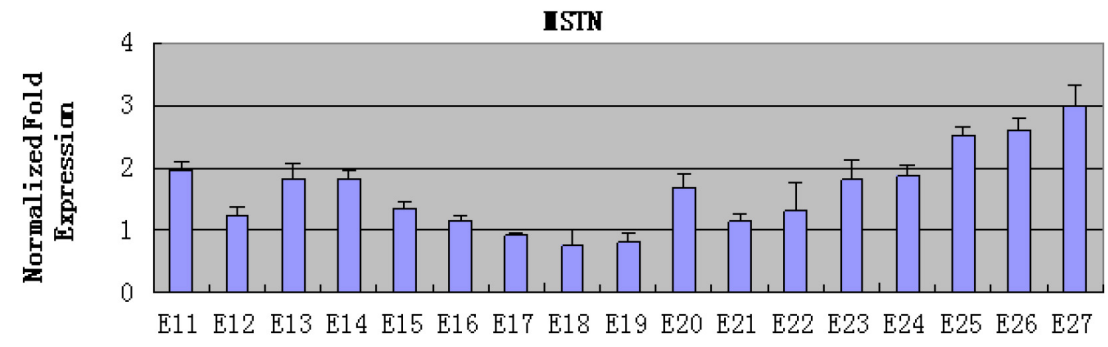

Dates of Age

Figure 8. Relative expression level of MSTN gene in the pectoral muscle of embryonic stage Pekin duck.

\section{DISCUSSION}

In avian species, the skeletal muscle undergoes development and maturation in structure and function during the incubation period. During this time, myoblasts are proliferating, differentiating into multinucleated myotubes, and finally forming mature muscle fibers (Picard et al., 2002). In an exploration of the regulation and mechanism of skeletal muscle development, Moore et al. (2005) reported that the cross-section area of myofiber and satellite cell mitotic activity in the pectoralis muscle decreased with age in late-term turkey embryos, which indicated that the skeletal muscle might undergo atrophy during the final days of incubation. Chen et al. (2012) also found that the pectoralis muscle mass, muscle fiber bundles, and myofibers crosssection area showed marked reductions from E22 to hatching in duck. In the present study, body weight increased with age, while the pectoral muscle nearly ceased growth after E20. This suggested that the fusion of muscle fibers was the predominant event in the pectoral muscle of Pekin duck after E20, and that there was no hypertrophy during this stage. Therefore, E20 might be the crucial point at which muscle fibers of Pekin duck transition from proliferation to fusion.

Studying the developmental morphological characteristics of various tissues could provide intuitive evidence for the development and pathological changes of these tissues. AlAli et al. (2009) investigated the correlation between gross anatomical topography, sectional 
sheet plastination, microscopic anatomy, and endoanal sonography of the anal sphincter complex in human males. Chen et al. (2006) found morphological changes of the skeletal muscle, tendon, and periosteum in senescence-accelerated mice (SAMP6) compared to age-matched normal SAMR1 mice. McClearn et al. (1995) explored the pervasiveness of myofiber degeneration and spatiotemporal patterns of degeneration during the development of head and neck muscles in chick embryos by evaluating morphological characteristics of muscle cells. In duck, Li et al. (2010) compared morphological characteristics of pectoral and leg muscle tissues during duck embryo stages to the neonatal stage through paraffin sections. Chen et al. (2012) studied the developmental transition of the pectoralis muscle from late-term duck embryos to neonates. In the current study, developmental morphological characteristics of Pekin duck pectoral muscles were investigated in the embryonic stage, and E20 was identified as the transition point (from proliferation to fusion) of the Pekin duck pectoral muscle. This suggested that the number of mono-nucleated myoblasts might be fixed before E20.

The myogenic regulatory factor (MRF) family (Tripathi et al., 2012), which includes MyoD, Myf5, MRF4, and MyoG, is important for muscle development. Two members of the family, MRF4 and MyoG, act as differentiation factors during skeletal muscle development, and MyoG is involved in muscle injury and repair after animal birth (Megeney and Rudnicki, 1995; Zhou and Bornemann, 2001; Wyszyńska-Koko et al., 2006). Myostatin (MSTN), also known as growth differentiation factor $8(G D F-8)$, is an important negative regulator in skeletal muscle development. Inactivation of the MSTN gene in mice (Mendias et al., 2008) or mutations in bovine (McPherron and Lee, 1997), sheep (Boman et al., 2010), and humans (Schuelke et al., 2004) result in a similar phenotype of increased muscle growth. Therefore, these three genes, MRF4, MSTN, and MyoG, are always used as indicators of skeletal development. In this study, the expression patterns of MRF4, MyoG, and MSTN indicated that E19 or E20 is the fastest point of pectoral muscle development, and that E19 or E20 is the crucial transition for Pekin duck pectoral muscle development during the embryonic stage.

In conclusion, analytical analysis demonstrated that body weight increased with age, while the pectoral muscle nearly ceased growth after embryonic day 20 (E20). Further morphological analysis of the Pekin duck pectoral muscle in the embryonic stage revealed that E20 was the transition point (from proliferation to fusion) of Pekin duck pectoral muscles. The expression patterns of MRF4, MyoG, and MSTN indicated that E19 or E20 is the fastest point of pectoral muscle development, and that E19 or E20 is the crucial transition for Pekin duck pectoral muscle development during the embryonic stage.

\section{ACKNOWLEDGMENTS}

We are grateful to Jun-Ying Yu and Qi Zhang for the preparation of our experiment, to Zhan-Bao Guo for data collection, and to Yan Liu, Yunsheng Zhang, and Jing Yang for reviewing the manuscript. Financial support was provided by The Supporting Technology Integration and Demonstration of Ecological Raising Pig (\#K332021202) and the earmarked fund for China Agriculture Research System (\#CARS-43-1).

\section{REFERENCES}

Al-Ali S, Blyth P, Beatty S, Duang A, et al. (2009). Correlation between gross anatomical topography, sectional sheet plastination, microscopic anatomy and endoanal sonography of the anal sphincter complex in human males. J. Anat. 
215: 212-220.

Boman IA, Klemetsdal G, Nafstad O, Blichfeldt T, et al. (2010). Impact of two myostatin (MSTN) mutations on weight gain and lamb carcass classification in Norwegian White Sheep (Ovis aries). Genet. Sel. Evol. $42: 4$.

Buckingham M (2006). Myogenic progenitor cells and skeletal myogenesis in vertebrates. Curr. Opin. Genet. Dev. 16: 525-532.

Callis TE, Chen JF and Wang DZ (2007). MicroRNAs in skeletal and cardiac muscle development. DNA Cell Biol. 26: 219-225.

Chen H, Yao XF, Emura S and Shoumura S (2006). Morphological changes of skeletal muscle, tendon and periosteum in the senescence-accelerated mouse (SAMP6): a murine model for senile osteoporosis. Tissue Cell 38: 325-335.

Chen W, Tangara M, Xu J and Peng J (2012). Developmental transition of pectoralis muscle from atrophy in late-term duck embryos to hypertrophy in neonates. Exp. Physiol. 97: 861-872.

Hartley RS, Bandman E and Yablonka-Reuveni Z (1992). Skeletal muscle satellite cells appear during late chicken embryogenesis. Dev. Biol. 153: 206-216.

Li L, Liu HH, Xu F, Si JM, et al. (2010). MyoD expression profile and developmental differences of leg and breast muscle in Peking duck (Anas platyrhynchos domestica) during embryonic to neonatal stages. Micron. 41: 847-852.

Liu HH, Wang JW, Zhang RP, Chen X, et al. (2012). In ovo feeding of IGF-1 to ducks influences neonatal skeletal muscle hypertrophy and muscle mass growth upon satellite cell activation. J. Cell. Physiol. 227: 1465-1475.

McClearn D, Medville R and Noden D (1995). Muscle cell death during the development of head and neck muscles in the chick embryo. Dev. Dyn. 202: 365-377.

McPherron AC and Lee SJ (1997). Double muscling in cattle due to mutations in the myostatin gene. Proc. Natl. Acad. Sci. U. S. A. 94: 12457-12461.

Megeney LA and Rudnicki MA (1995). Determination versus differentiation and the MyoD family of transcription factors. Biochem. Cell Biol. 73: 723-732.

Mendias CL, Bakhurin KI and Faulkner JA (2008). Tendons of myostatin-deficient mice are small, brittle, and hypocellular. Proc. Natl. Acad. Sci. U. S. A. 105: 388-393.

Moore DT, Ferket PR and Mozdziak PE (2005). Muscle development in the late embryonic and early post-hatch poult. Int. J. Poultry Sci. 4: 138-142.

Patel K, Christ B and Stockdale FE (2002). Control of muscle size during embryonic, fetal, and adult life. Results Probl. Cell Differ. 38: 163-186.

Picard B, Lefaucheur L, Berri C and Duclos MJ (2002). Muscle fibre ontogenesis in farm animal species. Reprod. Nutr. Dev. 42: 415-431.

Robert BW, Anne-Sophie B, Viola FG and Peter SZ (2010). Dynamics of muscle fibre growth during postnatal mouse development. Dev. Biol. 10: 21.

Sabourin LA and Rudnicki MA (2000). The molecular regulation of myogenesis. Clin. Genet. 57: 16-25.

Schuelke M, Wagner KR, Stolz LE, Hübner C, et al. (2004). Myostatin mutation associated with gross muscle hypertrophy in a child. N. Engl. J. Med. 350: 2682-2688.

Tripathi AK, Aparnathi MK, Vyavahare SS, Ramani UV, et al. (2012). Myostatin gene silencing by RNA interference in chicken embryo fibroblast cells. J. Biotechnol. 160: 140-145.

Velleman SG, Nestor KE, Coy CS and Anthony NB (2010). Effect of posthatch feed restriction on broiler breast muscle development and muscle transcriptional regulatory factor gene and heparan sulfate proteoglycan expression. Int. J. Poult. Sci. 9: 417-425.

Williams AH, Liu N, van Rooij E and Olson EN (2009). MicroRNA control of muscle development and disease. Curr. Opin. Cell Biol. 21: 461-469.

Wyszyńska-Koko J, Pierzchala M, Flisikowski K, Kamyczek M, et al. (2006). Polymorphisms in coding and regulatory regions of the porcine MYF6 and MYOG genes and expression of the MYF6 gene in m. longissimus dorsi versus productive traits in pigs. J. Appl. Genet. 47: 131-138.

Xu TS, Liu XL, Huang W and Zhou HL (2011). Estimates of genetic parameters for body weight and carcass composition in Pekin ducks. J. Anim. Vet. Adv. 10: 23-28.

Zhang J, Ying ZH, Tang ZL and Long LQ (2012). MicroRNA-148a promotes myogenic differentiation by targeting the ROCK1 gene. J. Biol. Chem. 287: 21093-21101.

Zhou Z and Bornemann A (2001). MRF4 protein expression in regenerating rat muscle. J. Muscle Res. Cell Motil. 22: 311-316.

Genetics and Molecular Research 12 (4): 6733-6742 (2013) 